\title{
UMA PRÁTICA DE PLANEJAMENTO PARTICIPATIVO DESENVOLVIDA NO INSTITUTO FEDERAL DO RIO GRANDE DO NORTE
}

\author{
F. C. M. FERNANDES \\ Instituto Federal do Rio Grande do Norte \\ E-mail: francisco.mariz@ifrn.edu.br
}

Artigo submetido em março/2012 e aceito em maio/2012

\section{RESUMO}

Este artigo descreve uma prática de planejamento participativo vivenciada no Instituto Federal de Educação, Ciência e Tecnologia do Rio Grande do Norte (IFRN), a partir de teorias e conceitos generalistas concebidos por estudiosos da ciência da administração acerca da função planejamento, constituindo-se como uma sistematização de referência operacional concreta. Trata-se de um modelo construído com base nos princípios de gestão democrática, tendo como principais instrumentos norteadores: o Projeto Político Pedagógico (PPP) unificado, trabalhado nos diversos Campi do IFRN com metodologia que integra os segmentos (discentes, docentes e técnico-administrativos) institucionais na definição de objetivos, metas e ações, consonantes com a função social do Instituto; o Plano de
Desenvolvimento Institucional (PDI), também elaborado com a participação da comunidade e que representa o esforço da Instituição em pensar seu desenvolvimento, em curto e médio prazo, de uma forma planejada coletivamente; e parâmetros oriundos de órgãos superiores (CONSUP, Ministério da Educação e órgãos de controle interno e/ou externo), além de avaliação diagnóstica da situação institucional. Nesse contexto, o Plano de Ação resulta, pois, de um processo de construção coletiva, envolvendo todos os Campi e a Reitoria, e cuja execução passa por monitoramento, acompanhamento e controle, com o objetivo de garantir a consecução dos objetivos propostos através das metas estabelecidas e, se necessário, corrigir rumos e superar eventuais dificuldades.

PALAVRAS-CHAVE: Descentralização; Gestão democrática; Planejamento participativo; Plano de Ação.

\section{A PARTICIPATORY PLANNING PRACTICE DEVELOPED AT THE FEDERAL INSTITUTE OF EDUCATION, SCIENCE AND TECHNOLOGY OF RIO GRANDE DO NORTE ABSTRACT}

\begin{abstract}
This article describes a practice of participatory planning experienced at the Federal Institute of Education, Science and Technology of Rio Grande do Norte (IFRN), established from general theories and conceptions designed by close students of the science of administration about the planning function, establishing itself as a concrete systematic reference operational. This is a model built on the principles of democratic management, having as main guiding instruments: the unified Political Pedagogical Project (PPP), worked in the various campuses of IFRN with methodology that integrates institutional segments (students, teachers and technicaladministrative) in the definition of goals, targets and actions, among the social function of the Institute; the
\end{abstract}

institutional Development Plan (IDP), also developed with participation of all community, which represents the effort of the institution in thinking about its own development, in short and medium term, in form that has been planned collectively; and parameters derived from governing bodies (CONSUP, Ministry of Education and organs of internal / or external control), and also diagnostic evaluation of the institutional situation. In this context, the Action Plan results, therefore, a collective construction process, involving all campuses and the Rectory, and the execution of which this plan involves tracking, monitoring and control, in order to ensure achieving goals through the established targets and, if necessary, correct the route and overcome difficulties.

KEY-WORDS: Decentralization, democratic management, participatory planning, Plan of Action. 


\section{UMA PRÁTICA DE PLANEJAMENTO PARTICIPATIVO DESENVOLVIDA NO INSTITUTO FEDERAL DO RIO GRANDE DO NORTE}

\section{CONSIDERAÇÕES INICIAIS}

Lei no. 11.892, de 29 de dezembro de 2008, que instituiu a Rede Federal de Educação Profissional, Científica e Tecnológica e criou os Institutos Federais de Educação, Ciência e Tecnologia, determina no caput dos seus artigos 9o e 11, respectivamente, que "cada Instituto Federal é organizado em estrutura multicampi, com proposta orçamentária anual identificada para cada campus e a reitoria, exceto no que diz respeito à pessoal, encargos sociais e benefícios aos servidores" e que "os Institutos Federais terão como órgão executivo a reitoria".

Esse tipo de organização multicampi e pluricurricular, com atuação nos diversos níveis da educação nacional e articulação do ensino com a pesquisa e extensão, conduz os Institutos Federais a uma nova institucionalidade e, consequentemente, exige novos procedimentos de gestão, tomando-se por referência as instituições que por transformação ou integração os originaram e que, nesse processo, precisam evoluir. De acordo com Morin (2000, p. 82):

"Toda evolução é fruto do desvio bem-sucedido cujo desenvolvimento transforma o sistema onde nasceu: desorganiza o sistema, reorganizandoo. As grandes transformações são morfogêneses, criadoras de formas novas que podem constituir verdadeiras metamorfoses. De qualquer maneira, não há evolução que não seja desorganizadora/reorganizadora em seu processo de transformação ou de metamorfose."

Nessa nova estruturação institucional, caberá à reitoria buscar a essência das funções estratégicas e táticas, cabendo-lhe a responsabilidade pela definição de políticas, supervisão e controle, ao passo que os campi, enquanto unidades de execução da ação educacional, são responsáveis pelo cumprimento dos objetivos finalísticos do Instituto Federal. Trata-se, pois, de uma abordagem inovadora que pretende viabilizar o funcionamento e o controle da organização em toda uma região, garantindo a oferta de uma educação pública eficaz e de qualidade.

Na prática, a proposta dos Institutos Federais compreende uma estruturação própria de uma organização composta de várias organizações, vislumbrando-se uma realidade de enfoque sistêmico, onde o Instituto Federal passa a ser um conjunto de unidades com gestão interdependente entre os campi e a reitoria, integrados por princípios institucionais estratégicos, com projeto político-pedagógico único e foco na justiça social e equidade.

Morin (2005, p. 133) define assim organização:

"é o encadeamento de relações entre componentes ou indivíduos que produz uma unidade complexa ou sistema, dotada de qualidades desconhecidas quanto aos componentes ou indivíduos. A organização liga de maneira inter-relacional os elementos ou acontecimentos ou indivíduos diversos que desde então se tornam os componentes de um todo. Ela assegura solidariedade e solidez relativa a estas ligações, assegurando então ao sistema uma certa possibilidade de duração apesar das 
perturbações aleatórias. A organização, portanto: transforma, produz, religa, mantém."

Nessa perspectiva, a "descentralização" entendida como função que compreende a transferência de poder do centro para as extremidades do sistema, funciona como os elos da cadeia hierárquica da estrutura que se comporta como rede.

No Instituto Federal de Educação, Ciência e Tecnologia do Rio Grande do Norte (IFRN), a Reitoria é o elo integrador de uma rede de dezesseis Campi atualmente em funcionamento: Apodi, Caicó, Central/Natal, Cidade Alta/Natal, Currais Novos, Educação à Distância, Ipanguaçu, João Câmara, Macau, Mossoró, Nova Cruz, Parnamirim, Pau dos Ferros, Santa Cruz, São Gonçalo do Amarante e Zona Norte/Natal; e três em implantação: Canguaretama, Ceará-Mirim e São Paulo do Potengi; conforme esquema representativo constante da figura 1.

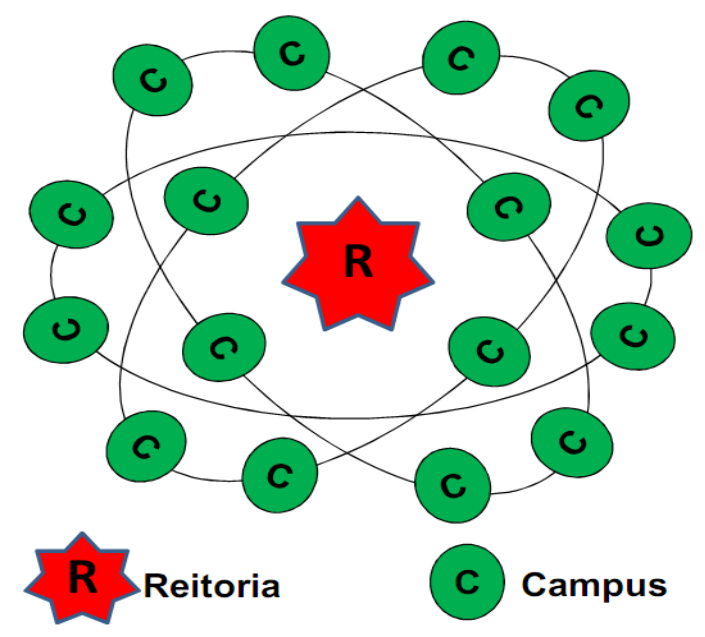

Figura 1 - Representação gráfica da integração Reitoria x Campi.

Como as Unidades estão distribuídas geograficamente por todo o Estado do Rio Grande do Norte, para que haja rapidez nas decisões vinculadas com a realidade, redução máxima de conflitos entre a gestão central e dos campi, motivação e responsabilização assumida nos vários níveis, é indispensável que o IFRN mantenha uma estruturação descentralizada que garanta o equilíbrio da coordenação e controle exercidos pela Reitoria e Colegiados com a autonomia administrativa das Unidades Escolares, observados também critérios de racionalização de trabalho, economicidade e efetividade.

Assumida no IFRN como prática institucional, a gestão democrática requer como princípio fundamental a construção de um processo permanente e contínuo de planejamento participativo cujo principal instrumento norteador de política é o projeto pedagógico unificado, trabalhado nos diversos Campi com metodologia que envolva os segmentos integrantes da comunidade escolar na definição de objetivos, metas e ações, consonantes com a função social do Instituto, bem como com o compromisso de execução do que foi planejado, disso resultando planos de ações anuais que devem responder aos desafios diagnosticados no Plano de Desenvolvimento Institucional (PDI).

Para Gemerasca (2004, p. 38): 
"Ao se optar pelo Planejamento Participativo precisamos ter clareza que quanto mais abertura dermos no sentido de garantir a participação das pessoas, maior transparência e credibilidade terá o processo de planejamento.

Entendemos que, embora seja complicado e de certa forma difícil garantir a participação dos diversos segmentos na construção e elaboração do plano, a riqueza do processo está na participação coletiva dos envolvidos. Entretanto, não basta que as pessoas garantam sua participação, é necessário que estejam realmente dispostas e comprometidas com a realização de um trabalho sério que envolve muita dedicação e muito esforço."

Através do planejamento, deve-se buscar a melhoria contínua da Instituição, garantir a realização das prioridades acadêmicas e administrativas, com eficácia e efetividade, bem como viabilizar a alocação de recursos para efetivação dos projetos e atividades, observados princípios de economicidade, além de subsidiar a tomada de decisão dos gestores. São pressupostos desse processo: abrangência sistêmica sobre todo o Instituto Federal de Educação, Ciência e Tecnologia do Rio Grande do Norte, avaliação continuada, inovação e racionalização de métodos, flexibilidade e interação com as funções administrativas de organização, direção e controle.

Outro pressuposto importante é a compreensão organizacional das áreas de dimensões estratégicas. Em outro estudo sobre os Institutos Federais, foram consideradas oito grandes áreas, a saber: administração, assuntos estudantis, ensino, extensão, gestão de pessoas, pesquisa e inovação, tecnologia da informação e planejamento e desenvolvimento institucional, conforme demonstrado na figura 2 (FERNANDES, 2011, p. 6):

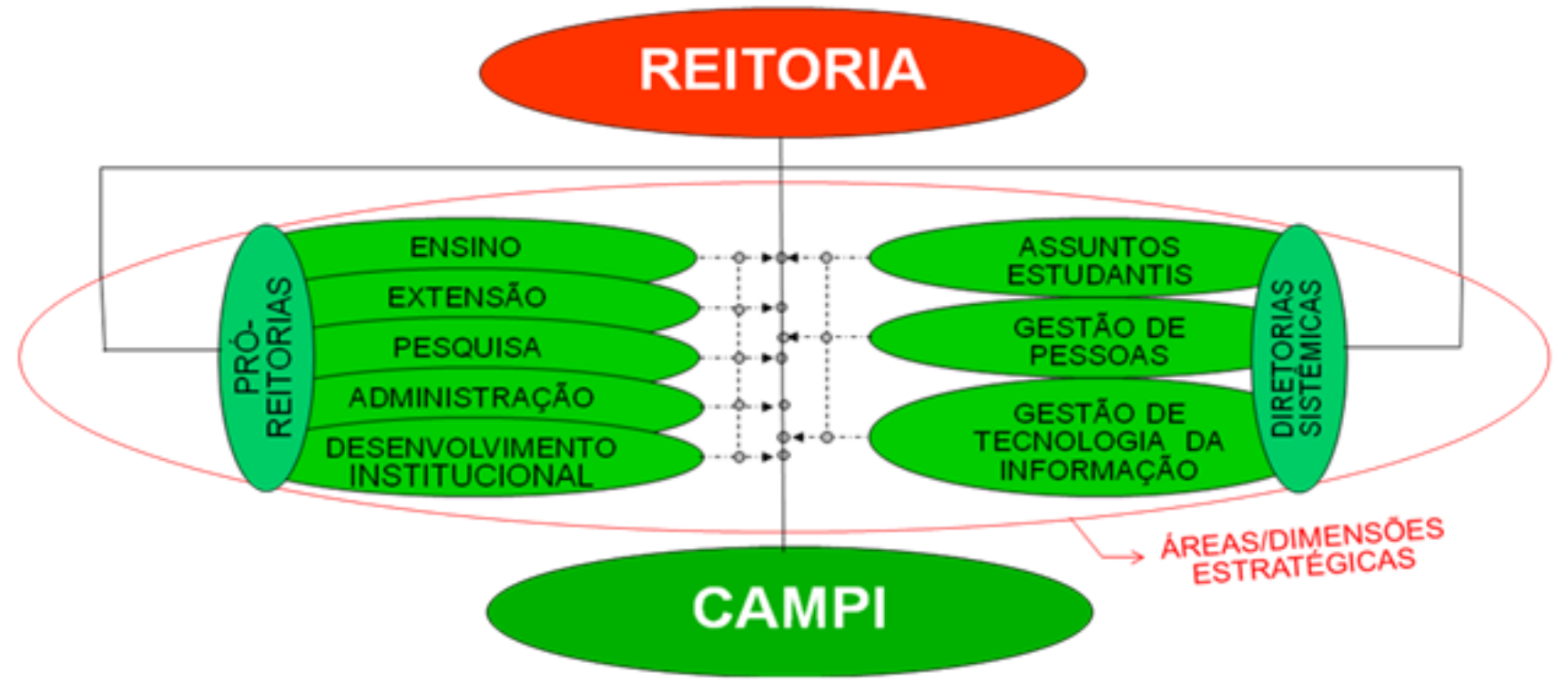

Figura 2 - Arranjo organizacional das áreas/dimensões estratégicas dos Institutos Federais. 
Entender a nova institucionalidade do IFRN é imprescindível para a estruturação de uma modelagem que viabilize autonomia para cada Campus desenvolver sua ação administrativa, atuando racional e harmonicamente com a Reitoria e com os demais Campi coirmãos. Esses fundamentos afastam a gestão do centralismo, levando-a para um ambiente colaborativo e de participação. Cada Campus, como organização, está submetido a forças externas e internas, transformando-se num espaço cultural com vínculos e especificidades comuns à rede que integra e com outras características que lhe são próprias. Como ferramentas da gestão, o planejamento e o controle devem eliminar o que comumente se denomina "ação de bombeiro", "função de delegado" e/ou "tática de maré", que fragiliza os dirigentes, porquanto, em tais situações, a administração se detém, muitas vezes, em "apagar incêndios", "resolver problemas" e/ou "ir para onde o vento leva".

\section{ELEMENTOS DE ESTRUTURAÇÃO DOS PLANOS}

$\mathrm{Na}$ estruturação dos planos, incluindo a orientação e o acompanhamento das ações planejadas e executadas, alguns elementos intervêm como indutores de políticas, balizadores da ação institucional e estratégias metodológicas.

\section{Planejamento estratégico}

O primeiro elemento é o Plano de Desenvolvimento Institucional (PDI), que é construído com a participação da comunidade acadêmica, tendo como instrumentos norteadores, para sua elaboração: a nova institucionalidade decorrente da legislação de criação dos Institutos Federais; a função social e o Projeto Político Pedagógico (PPP) da Instituição; os parâmetros das metas acordadas com o Ministério da Educação; a análise da cultura organizacional; e a avaliação dos cenários interno e externo. O PDI representa o esforço institucional em pensar seu desenvolvimento, em curto e médio prazo, de uma forma planejada coletivamente.

A elaboração do Plano 2009-2014 do IFRN foi coordenada por uma Comissão composta por representações de todos os Campi do Instituto e estruturada com base em roteiro de questões previamente definidas e discutidas com a comunidade acadêmica. Para oportunizar tal reflexão, além da criação de uma página virtual com link no sítio institucional e da disponibilização de correio eletrônico, foram realizados, em distintos momentos, seminários com a participação de especialistas externos, audiências públicas e reuniões, através dos quais os diversos segmentos que compõem o Instituto puderam colaborar com críticas, sugestões e proposições embasadas em suas competências técnicas, políticas, acadêmicas e profissionais.

Dessa maneira, foram discutidos, em todos os Campi da Instituição, aspectos considerados relevantes para a constituição do perfil institucional e a demarcação dos rumos possíveis e desejáveis para o Instituto, tais como: a função social em relação aos pressupostos do PPP, a previsão das ofertas educacionais em articulação com a vocação, os focos estratégicos e os limites de atuação institucional, além dos desafios decorrentes da nova institucionalidade e do atual contexto socioeconômico. A partir daí, foram determinadas as metas em cada uma das dimensões do 
funcionamento da Instituição com os respectivos indicadores que possibilitarão acompanhar e avaliar os níveis de sucesso e desenvolvimento do Instituto Federal.

Vale também salientar que, na base da construção desse PDI, estão diretrizes apontadas por instâncias superiores, bem como pelo Plano Plurianual de Gestão 2009-2011, construído de acordo com os resultados da avaliação institucional realizada nos anos de 2005 a 2007 e em consonância com proposições formuladas pela comunidade acadêmica nos fóruns de debates sobre gestão democrática ocorridos em 2007 durante o processo eleitoral para escolha dos dirigentes da instituição.

\section{Planejamento Anual}

O Plano de Ação do IFRN elaborado anualmente resulta de um processo de construção coletiva, tendo como referência os princípios da gestão democrática e de planejamento participativo, envolvendo todos os Campi e a Reitoria, através da constituição de comissões designadas com representações dos três segmentos (discentes, docentes e técnico-administrativos) institucionais. Constituem elementos referenciais estratégicos para a sua estruturação, além do PPP e do PDI, parâmetros oriundos de órgãos superiores (CONSUP, Ministério da Educação e órgãos de controle interno e/ou externo) e de avaliação diagnóstica da situação institucional vivenciada. Trata-se das matrizes geradoras e propulsoras das diretrizes institucionais sistêmicas, a partir das quais são constituídos os objetivos, as metas e as ações em cada uma das dimensões estratégicas do funcionamento institucional: administração, assuntos estudantis, ensino, extensão, gestão de pessoas, pesquisa e inovação, tecnologia da informação e planejamento e desenvolvimento institucional.

Dessa forma, o processo de planejamento realizado no exercício atual para o ano seguinte é subsidiado por resultados de avaliação realizada continuamente sobre a execução contemporânea. 0 processo se organiza de forma simples e objetiva o trabalho de elaboração do plano de ação em etapas. Inicialmente, desenvolve-se seminário com a equipe de dirigentes sistêmicos contemplando também outros ocupantes de cargos de direção e especialistas convidados, para avaliação de fatores externos e dos elementos referenciais estratégicos (PPP, PDI, parâmetros oriundos de órgãos superiores e de órgãos de controle interno e/ou externo), bem como da avaliação diagnóstica da situação institucional vivenciada, com o objetivo de homogeneizar informações e definições acerca do planejamento institucional, da execução orçamentária e controles.

Após isso, os resultados do seminário são debatidos e validados pelo Colégio de Dirigentes, passando a constituir-se como diretrizes estratégicas e prioridades sistêmicas para o novo exercício.

Num terceiro momento, através de uma ação coordenada pelo Reitor em visitas aos Campi, por ocasião do chamado Gabinete Itinerante ${ }^{1}$, são realizadas palestras visando sensibilizar e motivar a comunidade acadêmica, evidenciando a importância social do Instituto e a necessidade da construção de um planejamento realmente participativo e democrático, com o engajamento de todos, inclusive para que a comunidade se sinta corresponsável pela execução do que for planejado.

\footnotetext{
${ }^{1}$ O Gabinete Itinerante é uma iniciativa criada pela gestão do IFRN como forma de aproximar a Reitoria dos Campi e promover a integração institucional, com cronograma trimestral, no qual Reitor, Pró-Reitores e Diretores Sistêmicos percorrem todos os Campi do Instituto.
} 
Em continuidade, realizam-se, ainda, convenções sob a coordenação dos dirigentes das oito áreas de dimensões estratégicas, com o objetivo de embasar as lideranças dos Campi acerca das diretivas das respectivas áreas, bem como para estimular o debate e o início dos trabalhos das comissões responsáveis pela elaboração do planejamento em cada Campus. Essas comissões são constituídas por representantes de docentes, estudantes e servidores técnico-administrativos do Campus, sob a coordenação do Diretor-Geral.

Às convenções segue-se uma avaliação diagnóstica em cada Campus, observadas suas especificidades e os vínculos institucionais sistêmicos, tendo como resultante o programa de necessidades da Unidade Educacional. Cada Campus é entendido como uma organização, submetido a forças externas e internas, transformando-se num espaço cultural com vínculos e especificidades comuns à rede que integra e com outras características que lhe são próprias. Assim, em consonância com as políticas e valores do IFRN, a realidade situacional de cada Campus deve levar em conta o cenário que a comunidade escolar deseja e/ou projeta para os próximos anos. Devem ser considerados os fatores externos (econômicos, políticos, sociais e culturais da região), representados pelas oportunidades (situações facilitadoras da consecução dos objetivos) e pelas ameaças (condições desfavoráveis ao desenvolvimento das finalidades institucionais), bem como os fatores internos, a saber: pontos fortes "qualidades" que propiciam uma condição favorável frente ao ambiente onde a instituição se insere - e pontos fracos - "deficiências" que lhe imputam uma condição desfavorável no processo competitivo ou frente ao ambiente em que se insere.

Sob essa perspectiva, é importante que a fase diagnóstica seja apoiada em um bom levantamento de informações, inclusive que possam ser utilizadas como subsídio para a superação de dificuldades existentes, no tocante à comunidade, sua infraestrutura física e de equipamentos/materiais, recursos humanos disponíveis, formas de financiamento e mecanismos de execução de despesas e controle.

Considerando que planejar é prever e programar ações visando à transformação ou implementação de uma futura realidade em função de resultados desejados, adentra-se, em seguida, a fase de estruturação das propostas de projetos e atividades. É a oportunidade de a Instituição elencar o que pode e deve fazer em função da análise de suas necessidades e disponibilidades, traduzidas em justificativas, objetivos e metas. Nessa etapa de programação operacional, é fundamental ter elementos para explicar a importância efetiva da ação, quais os recursos necessários (materiais, humanos e financeiros), como e quando esta será realizada e de quem é a responsabilidade pela sua execução. Assim, com respaldo nos estudos, é efetivada a elaboração das propostas de ações e prioridades de cada Campus para o exercício seguinte, e submetido à validação das áreas sistêmicas.

Já em outro momento, seguindo a modelagem de rede estabelecida para o planejamento, volta-se, então, a integrar os estudos realizados pela Reitoria e pelos Campi, para compatibilizá-los dentro de uma visão de atuação sistêmica racional e harmonicamente compartilhada, nas áreas de administração, assuntos estudantis, ensino, extensão, gestão de pessoas, pesquisa e inovação, planejamento e desenvolvimento institucional e tecnologia da informação.

Uma vez concluída a compatibilização dos objetivos, metas e ações, é o momento da organização e equalização do orçamento-programa, que viabilizará a realização das ações planejadas, de 
acordo com os recursos disponíveis nos programas do Governo Federal, que compõem a programação orçamentária do IFRN.

Finalmente, atrelam-se ao trabalho de sistematização das metas institucionais programadas indicadores de avaliação indispensáveis para aferição de resultados, visando atender aos órgãos de controle externos e aperfeiçoar a gestão escolar.

Como resultante desse processo de planejamento realizado, surge o Plano de Ação, que deve ser entendido como um instrumento balizador da organização e das decisões da gestão tomadas numa perspectiva sistêmica, cuja essência fundamenta-se nos instrumentos norteadores da política institucional.

A elaboração do planejamento anual recebe o suporte de tecnologia da informação através do módulo de planejamento do Sistema Unificado de Administração Pública (SUAP), criado pela equipe de desenvolvimento de sistemas da Diretoria de Gestão de Tecnologia da Informação do IFRN, para informatização dos processos administrativos do Instituto, ferramenta que tem facilitado a gestão da instituição.

\section{Monitoramento e Controle}

O planejamento não termina com a conclusão do Plano de Ação, pois, tendo característica de processo, se insere e é compreendido como função cíclica de planejar, acompanhar, avaliar e replanejar. Assim, uma vez iniciada sua execução, surge a fase de acompanhamento, com o objetivo de garantir o atingimento dos objetivos propostos através das metas estabelecidas, como também, caso seja necessário, de corrigir rumos e superar dificuldades.

De forma sistematizada, esse acompanhamento é planificado através de seminários trimestrais que envolvem a reitoria e as comunidades acadêmicas, bem como os dirigentes sistêmicos e dos Campi, servindo os resultados para subsídio de decisões do Colégio de Dirigentes e de patamar para aperfeiçoamento do planejado ou em novo planejamento, em consonância com o momento que se encontre a ação.

Também nessa etapa operacional de execução, a gestão conta com o módulo de orçamento do Sistema SUAP, para o acompanhamento das descentralizações orçamentárias, bem como dos gastos realizados com os recursos orçamentários.

\section{CONSIDERAÇÕES CONCLUSIVAS}

No momento em que os Institutos Federais que compõem a rede federal de educação profissional, científica e tecnológica ainda buscam um modelo de gestão de identidade com os preceitos da Lei oㅗ 11.892/2008, quando muitos que fazem essas instituições ainda discutem questões executivas referentes a níveis de autonomia versus soberania e de descentralização versus centralização, a descrição da experiência do processo de planejamento desenvolvido no IFRN poderá colaborar nos estudos e 
debates que se desenvolvem nessas instituições. Trata-se de um exemplo prático de caso de planejamento em aplicação, cujos pressupostos estão alinhados com princípios de gestão democrática e participação da comunidade.

Nesse contexto, contudo, o pensamento e a ação não podem ficar aprisionados. Como afirma Gemerasca (2004, p. 50):

"Seguir mecanicamente um roteiro não nos garante a eficiência nem a eficácia do planejamento. É necessário estar atento às circunstâncias, aos novos estímulos e problemas que vão surgindo, a fim de adequar tecnicamente o "roteiro" às necessidades do grupo e da instituição que planeja."

Em todo caso, essa experiência apresenta um modelo de construção de planejamento participativo para um Instituto Federal, a partir de teorias e conceitos generalistas concebidos por estudiosos da ciência da administração acerca da função planejamento, constituindo-se, pois, como uma sistematização de referência operacional concreta. Naturalmente, como todo trabalho pioneiro, contém lacunas e falhas a serem preenchidas e/ou corrigidas em processo de aperfeiçoamento com base em reflexão continuada.

\section{REFERÊNCIAS}

1. BRASIL. Lei no 11.892, de 29 de dezembro de 2008 . Disponível em: http://www.presidencia.gov.br/ccivil 03/ Ato2007-2010/2008/Lei/L11892.htm. Acesso em: 01.fev.12.

2. FERNANDES, Francisco das Chagas de Mariz. "As dimensões estratégicas organizacionais dos Institutos Federais", Revista HOLOS: ISSN 1807 - 1600. Vol. 1. Natal: IFRN, 2011.

3. GEMERASCA, Maristela Peliçoli e GANDIN, Danilo. Planejamento participativo na escola: o que é e como se faz. 3.ed. São Paulo: Loyola, 2004.

4. MORIN, Edgar. O método 1: a natureza da natureza. Trad. Ilana Heineberg. Porto Alegre: Sulina, 2005.

5. MORIN, Edgar. Os sete saberes necessários à educação do futuro. São Paulo: Cortez, 2000. 